\title{
Patient Understanding of Body Mass Index (BMI) in Primary Care Practices: A Two-State Practice-based Research (PBR) Collaboration
}

\author{
Robert E. Post, MD, MS, Megha Mendiratta, MD, Treab Haggerty, MD, \\ Alexia Bozek, MD, Gregory Doyle, MD, Jun Xiang, PhD, and Dana E. King, MD, MS
}

Background: The concept of body mass index (BMI) may not be well understood by patients. The purpose of this study was to evaluate patients' knowledge of BMI in the primary care setting.

Methods: Adult patients seen in 18 practices in West Virginia and New Jersey were invited to complete a voluntary survey. The survey assessed the patient's baseline knowledge of BMI as well as demographic information and whether the patient had known chronic conditions associated with increased BMI, including hypertension, hyperlipidemia, diabetes mellitus, and sleep apnea.

Results: While the majority (59.9\%) of primary care patients knew the meaning of BMI and that it is related to obesity, there was little knowledge of BMI cutoff values; more than $80 \%$ of responses were incorrect when asked to define specific BMI levels and their meaning. Self-awareness of obesity was limited as well, with only $16.4 \%$ aware of their own personal BMI. Furthermore, nearly $70 \%$ of patients could not recall having discussed BMI with their physician.

Conclusion: Findings indicate low comprehension of the term BMI. Increasing awareness of BMI may help patients address this key risk factor and significantly affect public health. (J Am Board Fam Med 2015;28:475-480.)

Keywords: Obesity, Physician-Patient Relations

One of the most widely accepted tools for evaluating and monitoring obesity in the primary care setting is body mass index (BMI). Increased BMI is associated with risk for developing type 2 diabetes, hypertension, and cardiovascular disease, ${ }^{1-7}$ and losing weight helps to decrease this risk. ${ }^{8-12}$ Accordingly, overweight and obesity have been shown to increase health care costs, increase mortality, and significantly shorten life expectancy. ${ }^{13-16}$ Unfortu-

This article was externally peer reviewed.

Submitted 22 September 2014; revised 24 February 2015; accepted 27 February 2015

From the Department of Family Medicine, Virtua Health, Voorhees, NJ (REP, MM); and Department of Family Medicine, West Virginia University, Morgantown ( $\mathrm{TH}, \mathrm{AB}$, GD, JX, DEK).

Funding: This project was supported in part by the National Institute of General Medical Sciences (U54GM104942).

Conflict of interest: none declared.

Disclaimer: The content is solely the responsibility of the authors and does not necessarily represent the official views of the National Institutes of Health.

Corresponding author: Robert E. Post, MD, MS, Virtua Family Medicine Residency, 2225 Evesham Rd, Suite 101, Voorhees, NJ 08043 (E-mail: rpost@virtua.org). nately, recent estimates suggest that almost $70 \%$ of Americans are overweight and more than $35 \%$ are obese. $^{17}$

Patients are unlikely to lose weight in the absence of motivation, so if patients do not perceive themselves as being at risk, then they are unlikely to change. ${ }^{18}$ BMI may be a tool that can be used to help educate patients. If overweight or obese patients are not aware of their BMI, they may not realize their increased health risk and may therefore be less likely to want to reduce their weight to reduce health risk. ${ }^{19-21}$ This is where the physician may be influential in educating the patient.

If physicians can educate patients regarding their weight status, it may motivate them to make lifestyle changes. ${ }^{18}$ Multiple studies that have evaluated physician advice regarding smoking cessation, diet and exercise, and immunizations have shown an increased likelihood that patients would participate in these behaviors if the physician provided this guidance. ${ }^{22-24}$ Physician recommendations in each of these studies helped motivate the 
patients to change behaviors, especially those who were at high risk. ${ }^{22}$ Specifically in terms of obesity and weight management, physician counseling has been shown to be an effective driver of patient motivation to lose weight. ${ }^{25-28}$ Patient education about BMI and obesity can be effective, with reported weight loss of up to $2.3 \mathrm{~kg}$ in patients whose primary care physician counseled them for 10 to 15 minutes per month. ${ }^{29}$

For counseling to be effective, patients may need to be aware of the meaning of BMI and how it is used. Therefore, the purpose of this study was to evaluate baseline knowledge regarding BMI among a primary care patient population.

\section{Methods}

\section{Population/Recruitment}

Patients were recruited to participate in 2 states, West Virginia and New Jersey. Participants in West Virginia were a sample of patients being seen in June 2013 at 1 of 16 rural primary care practices in the West Virginia Practice-Based Research Network, and those in New Jersey were a sample from 2 large suburban practices in the Department of Family Medicine at Virtua Health. Researchers in West Virginia and New Jersey collaborated because of the differing rates of obesity in those states (26.3\% in New Jersey, $35.1 \%$ in West Virginia). ${ }^{30}$ The protocol was reviewed as exempt by the West Virginia University and Virtua Health institutional review boards.

Patients were approached in the waiting room of participating practices and offered an opportunity to participate in the survey. Patients who met the inclusion criterion were invited to complete the study survey. The inclusion criterion was any adult over the age of 18. Patients were excluded if they could not effectively communicate in English; had a previously known cognitive impairment that would affect their ability to complete the survey or follow directions (eg, mental retardation, dementia, psychosis); or had significant visual impairment. There was no penalty for declining to complete the survey. If patients chose to participate, they were asked to complete the survey before the office visit and return completed surveys to the front desk staff. Surveys then were placed in a sealed envelope and returned to the research center. The envelopes were accessed only by researchers for the purpose of data input. The surveys were identified by site but not by participant.

\section{Survey}

The survey (Table 1) consisted of 13 questions total: 8 questions regarding BMI knowledge and 5 demographic questions. Questions were reviewed and refined by content experts. The BMI knowledge questions were a combination of both openended questions, such as "What does BMI stand for?" and "A BMI of 30 or greater means. ..," and "yes or no" questions, such as "Have you heard of BMI before?" and "Do you know what your BMI is?" The first 5 of the BMI knowledge questions had a correct and incorrect answer, whereas the last 3 questions were subjective. Demographics collected in the survey were age, sex, height, and weight. The survey also assessed whether the patient had any chronic conditions associated with increased BMI, including hypertension, hyperlipidemia, diabetes mellitus, or sleep apnea.

\section{Statistical Analysis}

Demographic data for both West Virginia and New Jersey were analyzed both separately and to-

Table 1. Descriptive Statistics of Survey Patients' Body Mass Index Knowledge

\begin{tabular}{lcccc}
\hline BMI Knowledge Questions & West Virginia & New Jersey & West Virginia and New Jersey & $P$ Value* \\
\hline What does BMI stand for? & 60.3 & 58.8 & 59.9 & .75 \\
BMI is related to what medical concern? & 50.1 & 49.3 & 49.9 & .87 \\
A BMI of 25 or greater means. . & 18.0 & 16.2 & 17.5 & .64 \\
A BMI of 30 or greater means. . & 18.5 & 12.8 & 16.8 & .12 \\
A BMI of 40 or greater means. . & 14.3 & 14.9 & 14.5 & .88 \\
Do you know what your BMI is? & 18.7 & 12.2 & 16.8 & .07 \\
\hline
\end{tabular}

Data are percentages choosing the correct answer.

${ }^{*} \chi^{2}$ Comparison of responses of body mass index (BMI) knowledge questions between patients from West Virginia and patients from New Jersey. 
gether. The primary outcome measure was the proportion of patients who knew what the letters "BMI" stood for, which was determined as a correct answer only if the patient recorded "body mass index" as the answer. Secondary measures included the presence of obesity-related comorbid conditions or previously having a discussion about BMI with a doctor. Finally, a score-of a possible 5 points-regarding the number of correct answers to the 5 BMI knowledge questions was calculated for each patient. BMI knowledge was categorized as low for a score of 0 to 2 and high for a score of 3 to 5 .

All data were entered into an Excel spreadsheet (Microsoft Corp., Redmond, WA). Descriptive statistics of the general population, prevalence of categorical BMI status, and knowledge were performed. $\chi^{2}$ Analysis was used to evaluate whether there were associations between patient knowledge of BMI and patient BMI. Patients' comorbid conditions in relation to BMI also were assessed using $\chi^{2}$ analysis. Logistic regression for demographic data and comorbid factors associated with categorized patient's BMI knowledge scores was analyzed. Two-sided $P$ values $<.05$ were determined to be statistically significant. Data were analyzed using SAS version 9.3 (SAS Institute, Inc., Cary, NC).

\section{Results}

Researchers in New Jersey and West Virginia received completed surveys from 157 (of 200) and 358 (of 500) participants, respectively. Total response rate was 515 of 700 surveys, or $73.6 \%$. Demographic data from each state were analyzed. There was not a significant difference in the age, sex, comorbid conditions, or calculated BMI between the 2 state populations (Table 2). The proportion of participants who correctly answered the BMI knowledge questions was also similar between New Jersey and West Virginia (Table 1). Therefore, because the results of the main outcome were similar, the samples from each state were determined to be similar and further analysis was conducted on the sample population as a whole.

About $59.9 \%$ of the sample knew that BMI stood for "body mass index." Furthermore, 49.9\% understood what medical concerns were related to BMI. Only a small minority of patients could correctly define BMI by classification; $17.5 \%$ knew

Table 2. Descriptive Statistics of Body Mass Index Survey Patients' Demographic Characteristics

\begin{tabular}{|c|c|c|c|c|}
\hline Characteristics & West Virginia & New Jersey & $\begin{array}{l}\text { West Virginia and } \\
\text { New Jersey }\end{array}$ & $P$ Value* \\
\hline Age, years $($ mean $\pm S D)$ & $48.9 \pm 17.4$ & $48.4 \pm 17.2$ & $48.7 \pm 17.3$ & .77 \\
\hline \multicolumn{5}{|l|}{ Sex $(\%)$} \\
\hline Male & 42.2 & 47.3 & 43.7 & .29 \\
\hline Female & 57.8 & 52.7 & 56.3 & \\
\hline $\begin{array}{l}\text { Calculated BMI based on self-reported height } \\
\text { and weight (mean } \pm \mathrm{SD})\end{array}$ & $28.9 \pm 7.1$ & $29.5 \pm 7.3$ & $29.1 \pm 7.2$ & .46 \\
\hline \multicolumn{5}{|l|}{$\begin{array}{l}\text { Weight status based on BMI calculated from } \\
\text { self-reported height and weight (\%) }\end{array}$} \\
\hline Underweight (BMI <18.5) & 2.3 & 1.4 & 2.0 & .91 \\
\hline Normal weight (BMI 18.5-24.9) & 27.8 & 28.4 & 27.9 & \\
\hline Overweight (BMI 25-29.9) & 31.2 & 31.8 & 31.3 & \\
\hline Obese $(\mathrm{BMI} \geq 30$ ) & 38.8 & 38.5 & 38.7 & \\
\hline \multicolumn{5}{|l|}{ Presence of comorbid conditions (\%) } \\
\hline Hypertension (self-reported) & 40.1 & 41.9 & 40.6 & .71 \\
\hline Hyperlipidemia (self-reported) & 33.5 & 25.7 & 31.2 & .08 \\
\hline Diabetes mellitus (self-reported) & 13.9 & 15.5 & 14.4 & .64 \\
\hline Sleep apnea (self-reported) & 10.1 & 8.8 & 9.7 & .65 \\
\hline Obesity (based on calculated BMI) & 38.8 & 38.5 & 38.7 & .95 \\
\hline
\end{tabular}

${ }^{*}$ Comparisons of demographic characteristics between patients from West Virginia and patients from New Jersey using $t$ test for continuous variables (age and calculated body mass index [BMI]) or $\chi^{2}$ test for categorical variables (sex, BMI group, and presence of comorbid conditions).

$\mathrm{SD}$, standard deviation. 
that a BMI of 25.0 to $29.9 \mathrm{~kg} / \mathrm{m}^{2}$ signaled overweight, $16.8 \%$ knew that a BMI of 30.0 to 39.9 $\mathrm{kg} / \mathrm{m}^{2}$ was obese, and $14.5 \%$ knew that a BMI of $\geq 40.0 \mathrm{~kg} / \mathrm{m}^{2}$ was morbidly obese (Table 1 ). In the 2 states combined, $60.5 \%$ of participants claimed that they had heard of BMI before this survey, with no statistical difference between the states. Of participants from West Virginia, however, 19.7\% reported having ever discussed BMI with their physician, versus $10.8 \%$ of participants from New Jersey $(P=.02)$.

Patient BMI was inversely related to a patient being able to recall their own BMI; $10.9 \%$ of patients with a $\mathrm{BMI} \geq 30 \mathrm{~kg} / \mathrm{m}^{2}$ knew their own BMI, compared with $20.4 \%$ of patients with a BMI $<30 \mathrm{~kg} / \mathrm{m}^{2}$ (odds ratio, $0.48 ; 95 \%$ confidence interval, 0.28-0.82). Patients who were obese also were more likely to have comorbid conditions such as hypertension, hyperlipidemia, diabetes mellitus, or sleep apnea than those who were not obese (Table 3).

Using logistic regression analysis, age, sex, comorbid conditions, and BMI were not related to knowledge of BMI. Patients saying they had had a discussion about BMI with their physician, how- ever, was significantly associated with patients' BMI knowledge score (odds ratio, 2.49; 95\% confidence interval, 1.58-3.90).

\section{Discussion}

This study demonstrates a lack of understanding of BMI among primary care patients in these practices studied. Patients were frequently unable to identify correctly their own BMI, and about half of the patients surveyed did not know what medical conditions were related to BMI. These data are of concern given the high prevalence of obesity in the United States. ${ }^{17}$ These data were gathered in states with different prevalences of obesity but showed similar results, suggesting that low baseline knowledge of BMI may be present regardless of community obesity levels.

Evidence supports that people often do not have good insight into their own overweight status. ${ }^{31}$ The ability for a patient to identify themselves as being overweight has a correlation with the patient's desire to lose weight. ${ }^{32}$ Thus, patients' limited knowledge of the meaning of BMI and their own BMI level is particularly concerning for the

Table 3. Responses of Body Mass Index Knowledge Questions and Comorbid Conditions for Patients With Body Mass Index $<30$ versus Patients With Body Mass Index $\geq 30$ (West Virginia and New Jersey)

\begin{tabular}{|c|c|c|c|c|c|}
\hline $\begin{array}{l}\text { BMI Knowledge Questions and Comorbid } \\
\text { Conditions }\end{array}$ & $\begin{array}{c}\text { Overall } \\
(\mathrm{n}=511)\end{array}$ & $\begin{array}{l}\text { Patients With } \\
\text { BMI <30 } \\
(\mathrm{n}=307)\end{array}$ & $\begin{array}{l}\text { Patients With } \\
\text { BMI >30 } \\
(\mathrm{n}=194)\end{array}$ & $\begin{array}{l}\text { Odds Ratio } \\
(95 \% \mathrm{CI})^{*}\end{array}$ & $P$ Value $^{\dagger}$ \\
\hline \multicolumn{6}{|l|}{ Knowledge questions } \\
\hline What does BMI stand for? ${ }^{\ddagger}$ & 59.9 & 60.9 & 59.3 & $0.93(0.65-1.35)$ & .72 \\
\hline $\mathrm{BMI}$ is related to what medical concern? ${ }^{\ddagger}$ & 49.9 & 50.2 & 50.0 & $0.99(0.69-1.42)$ & .97 \\
\hline A BMI of 25 or greater means. . . & 17.5 & 17.6 & 17.1 & $0.97(0.60-1.56)$ & .89 \\
\hline A BMI of 30 or greater means. . . & 16.8 & 15.6 & 19.1 & $1.27(0.79-2.04)$ & .32 \\
\hline A BMI of 40 or greater means. . . & 14.5 & 13.4 & 16.0 & $1.23(0.74-2.05)$ & .41 \\
\hline Do you know what your BMI is? ${ }^{\ddagger}$ & 16.8 & 21.4 & 10.4 & $0.43(0.25-0.73)$ & .002 \\
\hline Have you heard of BMI before this survey? $\$$ & 60.5 & 63.4 & 58.0 & $0.80(0.55-1.15)$ & .23 \\
\hline $\begin{array}{l}\text { Has your doctor ever discussed BMI with } \\
\text { you? } \$\end{array}$ & 17.1 & 16.6 & 18.1 & $1.11(0.69-1.79)$ & .66 \\
\hline \multicolumn{6}{|l|}{ Comorbid conditions (\%) } \\
\hline Hypertension & 40.6 & 31.7 & 55.5 & $2.69(1.85-3.90)$ & $<.001$ \\
\hline Hyperlipidemia & 31.2 & 26.7 & 38.0 & $1.68(1.14-2.48)$ & .008 \\
\hline Diabetes mellitus & 14.4 & 9.5 & 22.6 & $2.78(1.67-4.64)$ & $<.001$ \\
\hline Sleep apnea & 9.7 & 5.3 & 16.4 & $3.49(1.85-6.59)$ & $<.001$ \\
\hline
\end{tabular}

* Odds ratio of body mass index (BMI) knowledge questions or comorbid conditions, comparing patients with a BMI $\geq 30.0$ with patients with a BMI $<30.0$.

${ }^{+} \chi^{2}$ Comparison of responses of BMI knowledge questions between patients with a BMI $<30.0$ and patients with a BMI $\geq 30.0$.

${ }^{\ddagger}$ Percentage with the correct answer.

\$Percentage answering "yes."

CI, confidence interval. 
prospects of motivating patients to reduce the risks associated with overweight and obesity. Discussing the definition of BMI may be the first step for primary care physicians to open a discussion with patients regarding the risks of obesity. Then the doctor can make the patient aware of their own BMI level and discuss with the patient how BMI correlates to medical problems they may currently have or may develop in the future. When addressing this with patients, physicians should use terms such as BMI, weight, or weight problem, which have been shown to be desirable terms among patients. ${ }^{33}$

A discussion regarding BMI may help address patients' misconceptions about weight and their own weight status. This is reinforced by our findings of increased BMI knowledge among those who had a discussion with their physician. According to this study, the patient's perception is that discussions regarding BMI and weight do not occur often. Only about a third of the study participants had had a discussion of BMI with their physician. One previous study suggested that physicians have a lower level of respect for obese patients compared with normal-weight patients. ${ }^{34}$ Therefore, physicians need to recognize whether they personally have this bias and reconcile that to treat patients appropriately and have necessary discussions regarding BMI and weight.

Discussion of BMI may be an underused tool not only for the patient to be informed but also for them to understand the risks associated with obesity. With the increasing use of electronic health records, BMI may be added as an extra "vital sign," with possible physician prompts to initiate a discussion if a BMI is at a specific threshold. In previous research, documentation of a patient's status as overweight or obese in the medical record was demonstrated to increase discussions about obesity between physicians and patients. ${ }^{35}$

\section{Limitations}

This study was conducted using convenience samples from 2 states, and the measures collected in this survey design were self-reported by the patient, which may have led to some inaccuracies in the self-report of height and weight. Socioeconomic status and race were not assessed in this survey, but these are factors that might have affected this study's findings because there are associations between socioeconomic status, race, and obesity. ${ }^{36}$ Finally, patients were surveyed while they were waiting to see a physician, and some anxiety regarding their upcoming doctor visit may have affected their recall or concentration level, possibly underestimating their BMI knowledge.

\section{Conclusions}

Our findings indicate a low rate of comprehension of BMI, including the relationship of increased BMI to chronic disease, among patients surveyed. A majority of patients did not know their own BMIs and could not recall discussing their BMI with physicians. These findings have implications for possible ways to address obesity in the community, specifically in terms of physicians educating patients about BMI, its relation to chronic diseases, and the patients' own BMI. Educating patients about $\mathrm{BMI}$ and relating their BMI to their weightrelated comorbidities may motivate patients to address their weight issues.

\section{References}

1. Arnlöv J, Sundström J, Ingelsson E, Lind L. Impact of BMI and the metabolic syndrome on the risk of diabetes in middle-aged men. Diabetes Care 2011; 34:61-5.

2. Narayan KM, Boyle JP, Thompson TJ, Gregg EW, Williamson DF. Effect of BMI on lifetime risk for diabetes in the U.S. Diabetes Care 2007;30:1562-6.

3. Nagaya T, Yoshida H, Takahashi H, Kawai M. Increases in body mass index, even within non-obese levels, raise the risk for Type 2 diabetes mellitus: a follow-up study in a Japanese population. Diabet Med 2005;22:1107-11.

4. Dotevall A, Johansson S, Wilhelmsen L, Rosengren A. Increased levels of triglycerides, BMI and blood pressure and low physical activity increase the risk of diabetes in Swedish women. A prospective 18-year follow-up of the BEDA study. Diabet Med 2004;21: 615-22.

5. Mokdad AH, Ford ES, Bowman BA, et al. Prevalence of obesity, diabetes, and obesity-related health risk factors, 2001. JAMA 2003;289:76-9.

6. Hirani V, Zaninotto P, Primatesta P. Generalised and abdominal obesity and risk of diabetes, hypertension and hypertension-diabetes co-morbidity in England. Public Health Nutr 2008;11:521-7.

7. Burke GL, Bertoni AG, Shea S, et al. The impact of obesity on cardiovascular disease risk factors and subclinical vascular disease: the Multi-Ethnic Study of Atherosclerosis. Arch Intern Med 2008; 168:928-35.

8. Diabetes Prevention Program Research Group, Knowler WC, Fowler SE, Hamman RF, et al. 10year follow-up of diabetes incidence and weight loss 
in the Diabetes Prevention Program Outcomes Study. Lancet 2009;374:1677-86.

9. Lindström J, Peltonen M, Eriksson JG, et al. Highfibre, low-fat diet predicts long-term weight loss and decreased type 2 diabetes risk: the Finnish Diabetes Prevention Study. Diabetologia 2006;49:912-20.

10. Hamman RF, Wing RR, Edelstein SL, et al. Effect of weight loss with lifestyle intervention on risk of diabetes. Diabetes Care 2006;29:2102-7.

11. Moore LL, Visioni AJ, Wilson PW, et al. Can sustained weight loss in overweight individuals reduce the risk of diabetes mellitus? Epidemiology 2000;11: 269-73.

12. Vinciguerra F, Baratta R, Farina MG, et al. Very severely obese patients have a high prevalence of type 2 diabetes mellitus and cardiovascular disease. Acta Diabetol 2013;50:443-9.

13. Seidell JC, Visscher TLS, Hoogeveen RT. Overweight and obesity in the mortality rate data: current evidence and research issues. Med Sci Sports Exerc 1999;31(11 Suppl):S597-601.

14. Allison DB, Fontaine KR, Manson JE, Stevens J, VanItallie TB. Annual deaths attributable to obesity in the United States. JAMA 1999;282:1530-8.

15. Allison DB, Zannolli R, Narayan KM. The direct health care costs of obesity in the United States. Am J Public Health 1999;89:1194-9.

16. Fontaine KR, Redden DT, Wang C, Westfall AO, Allison DB. Years of life lost due to obesity. JAMA 2003;289:187-93.

17. Flegal KM, Carroll MD, Kit BK, Ogden CL. Prevalence of obesity and trends in the distribution of body mass index among US adults, 1999-2010. JAMA 2012;307:491-7.

18. Post RE, Mainous AG 3rd, Gregorie SH, Knoll ME, Diaz VA, Saxena SK. The influence of physician acknowledgment of patients' weight status on patient perceptions of overweight and obesity in the United States. Arch Intern Med 2011;171:316-21.

19. Baranowski T, Cullen KW, Nicklas T, Thompson D, Baranowski J. Are current health behavioral change models helpful in guiding prevention of weight gain efforts? Obes Res. 2003;11(Suppl):23S43S.

20. Deville-Almond J, Tahrani AA, Grant J, Gray M, Thomas GN, Taheri S. Awareness of obesity and diabetes: a survey of a subset of British male drivers. Am J Mens Health 2011;5:30-7.

21. Moore SE, Harris C, Wimberly Y. Perception of weight and threat to health. J Natl Med Assoc 2010; 102:119-24.

22. Wray RJ, Jupka K, Ross W, Dotson D, Whitworth AR, Jacobsen H. How can you improve vaccination rates among older African Americans? J Fam Pract 2007;56:925-9.

23. Greenlund KJ, Giles WH, Keenan NL, Croft JB,
Mensah GA. Physician advice, patient actions, and health-related quality of life in secondary prevention of stroke through diet and exercise. Stroke 2002;33: 565-70.

24. Frank E, Winkleby MA, Altman DG, Rockhill B, Fortmann SP. Predictors of physician's smoking cessation advice. JAMA 1991;266:3139-44.

25. Jay M, Gillespie CC, Schlair S, Sherman S, Kalet AL. Physicians' use of the 5As in counseling obese patients: is the quality of counseling associated with patients' motivation and intention to lose weight? BMC Health Serv Res 2010;10:159.

26. Kant AK, Miner P. Physician advice about being overweight: association with self reported weight loss, dietary, and physical activity behaviors of US adolescents in the National Health and Nutrition Examination Survey, 1999-2002. Pediatrics 2007; 119:e142-7.

27. Huang J, Yu H, Marin E, Brock S, Carden D, Davis T. Physicians' weight loss counseling in two public hospital primary care clinics. Acad Med 2004;79: 156-61.

28. Rose SA, Poynter PS, Anderson JW, Noar SM, Conigliaro J. Physician weight loss advice and patient weight loss behavior change: a literature review and meta-analysis of survey data. Int J Obes (Lond) 2013;37:118-28.

29. Carvajal R, Wadden TA, Tsai AG, Peck K, Moran CH. Managing obesity in primary care practice: a narrative review. Ann N Y Acad Sci 2013;1281:191206.

30. Obesity prevalence maps. Prevalence of self-reported obesity among U.S. adults by state and territory, BRFSS, 2013. Atlanta: Centers for Disease Control and Prevention; 2014. Available from: http://www.cdc.gov/obesity/data/table-adults.html. Accessed on December 29, 2014.

31. Chang VW, Christakis NA. Self-perception of weight appropriateness in the United States. Am J Prev Med. 2003;24:332-9.

32. Lemon SC, Rosal MC, Zapka J, Borg A, Andersen V. Contributions of weight perceptions to weight loss attempts: differences by body mass index and gender. Body Image 2009;6:90-6.

33. Volger S, Vetter ML, Dougherty M, et al. Patients' preferred terms for describing their excess weight: discussing obesity in clinical practice. Obesity (Silver Spring) 2012;20:147-50.

34. Huizinga MM, Cooper LA, Bleich SN, Clark JM, Beach MC. Physician respect for patients with obesity. J Gen Intern Med 2009;24:1236-9.

35. Waring ME, Roberts MB, Parker DR, Eaton CB. Documentation and management of overweight and obesity in primary care. J Am Board Fam Med 2009; 22:544-52.

36. McLaren L. Socioeconomic status and obesity. Epidemiol Rev 2007;29:29-48. 